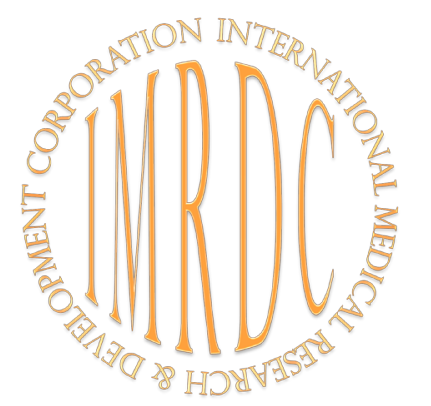

\title{
Results of Off-Pump Coronary Artery Bypass Surgery in Patients with EuroSCORE $\geq 5$
}

\author{
Islamjan M. Sharipov, PhD*; Shavkat I. Karimov, $\mathrm{PhD}, \mathrm{ScD}$; \\ Ravshanbek D. Kurbanov, PhD, ScD \\ Republican Specialized Center of Cardiology \\ Tashkent, Uzbekistan
}

\begin{abstract}
Background: The lack of reliable data on the possibility, safety and results of OPCABG in patients with high surgical risk hinders the further wide introduction into clinical practice of such operations. In this regard, conducting a comparative evaluation of the results of OPCABG in patients with low and high surgical risk seems to us a worthwhile project.

Materials and Methods: During the period between 2015 and 2017, 310 OPCABG operations were performed. Patients were divided into 2 groups depending on the EuroSCORE risk calculator value. Group 1 consisted of 130 (41.9\%) patients with a high surgical risk (EuroSCORE $\geq 5$ ), and Group 2 consisted of 180 (58.1\%) patients with a low surgical risk (EuroSCORE $<5$ ).

Results: We could not find between the two groups significant differences in the number of mean grafts per patients (3.12 in Group 1 and 3.13 in Group 2), in operation times, or in the level of morbidity and mortality (1.5\% in Group 1 and $1.2 \%$ in Group 2). All intraoperative conversions to on-pump CABG (5 cases or 3.8\%) occurred in patients of Group $1(P=0.008)$.

Conclusion: The OPCABG operation in patients of high-risk group is a safe method and can be performed without compromising the completeness of myocardial revascularization with the same low mortality as in low-risk patients. The most common type of complication in high-risk patients is on-pump conversion, which at earlier and planned implementation is not reflected significantly at the level of hospital mortality. (International Journal of Biomedicine. 2019;9(1):13-18.)
\end{abstract}

Key Words: off-pump CABG $\bullet$ high-risk patients $\bullet$ EuroSCORE $\bullet$ myocardial revascularization

\section{Abbreviations}

AF, atrial fibrillation; CABG, coronary artery bypass grafting; LAD, left anterior descending artery; LIMA, left internal mammary artery; LVEF, left ventricular ejection fraction; LMS, left main stem; OPCABG, off-pump CABG.

\section{Introduction}

The first two decades of the 21 st century were characterized by the introduction into clinical practice, and distribution, of OPCABG surgery without artificial blood circulation. Most of the studies carried out to date have been based on the study of the results of OPCABG in patients with low surgical risk in comparison with similar patients who had a conventional on-pump CABG. The lack of reliable data on the possibility, safety and results of OPCABG in patients with

*Corresponding author: Islamjan Sharipov, PhD. Department of Cardiac Surgery, Republican Specialized Center of Cardiology. Tashkent, Uzbekistan.E-mail: islamsharipov@mail.ru high surgical risk hinders the further wide introduction into clinical practice of such operations. In this regard, conducting a comparative evaluation of the results of OPCABG in patients with low and high surgical risk seems to us a worthwhile project.

\section{Material and Methods}

In the Department of Cardiac Surgery of the Republican Specialized Center of Cardiology, during the period between 2015 and 2017, 310 OPCABG operations were performed. Patients were divided into 2 groups depending on the EuroSCORE risk calculator value. Group 1 consisted of 130 $(41.9 \%)$ patients with a high surgical risk (EuroSCORE $\geq 5$ ), 
and Group 2 consisted of 180 (58.1\%) patients with a low surgical risk (EuroSCORE $<5)$.

Examination of clinical and demographic data in the groups showed (Table 1) that the mean age of patients in Group 1 was significantly higher than in Group 2 (63.9 against 57.8 years, respectively). In Group 1, the percentage of women was 2 times higher than in Group 2. About one-third of patients in each group had concomitant pathology, like obesity $(31.5 \%$ and $38.8 \%$ ) and diabetes (34.6\% and $27.4 \%)$, and their distribution in both groups was relatively homogeneous. There was a statistically significant difference in the number of patients with chronic lung pathology (35.4\% in Group 1 versus $22.8 \%$ in Group 2) and chronic renal pathology (16.9\% in Group 1 versus $8.9 \%$ in Group 2). About two-thirds of patients in each group had a previous history of MI. Acute coronary syndrome (ACS) was found in $34.1 \%$ of cases in Group 1 vs. $5.6 \%$ of cases in Group $2(P<0.001)$. The majority of patients in both groups (93\% and $97.2 \%)$ had angina pectoris.

Table 1.

Preoperative demographic and clinical data

\begin{tabular}{|c|c|c|c|}
\hline Variable & Group 1 & Group 2 & P-value \\
\hline Women & $30(23.1 \%)$ & $20(11.1 \%)$ & 0.005 \\
\hline Age, years & $63.98 \pm 6.8$ & $57.84 \pm 6.1$ & $<0.001$ \\
\hline Obesity & $41(31.5 \%)$ & $68(38.0 \%)$ & 0.489 \\
\hline COPD & $46(35.4 \%)$ & $41(22.8 \%)$ & 0.015 \\
\hline $\mathrm{DM}$ & $45(34.6 \%)$ & $49(27.4 \%)$ & 0.245 \\
\hline Chronic renal disease & $22(16.9 \%)$ & $16(8.9 \%)$ & 0.033 \\
\hline History of MI & $101(77.7 \%)$ & $113(62.8 \%)$ & 0.015 \\
\hline ACS & $44(34.1 \%)$ & $10(5.6 \%)$ & $<0.001$ \\
\hline $\begin{array}{l}\text { Symptoms: } \\
\text { angina } \\
\text { dyspnea }\end{array}$ & $\begin{array}{c}120(93.0 \%) \\
76(59.4 \%)\end{array}$ & $\begin{array}{c}173(97.2 \%) \\
67(37.6 \%)\end{array}$ & $\begin{array}{c}0.084 \\
<0.001\end{array}$ \\
\hline $\begin{array}{l}\text { Single-vessel disease } \\
\text { Two-vessel disease } \\
\text { Three-vessel disease }\end{array}$ & \begin{tabular}{|c|}
$3(2,5 \%)$ \\
$17(14.2 \%)$ \\
$100(83.3 \%)$ \\
\end{tabular} & \begin{tabular}{|c|}
$4(2,4 \%)$ \\
$20(12.1 \%)$ \\
$141(85.5 \%)$ \\
\end{tabular} & 0.877 \\
\hline LMS disease (or its equivalent) & $56(47.1 \%)$ & $74(45.1 \%)$ & 0.747 \\
\hline $\begin{array}{l}\text { Carotid artery lesion }>50 \% \text { : } \\
\text { One-sided } \\
\text { Two-sided }\end{array}$ & $\begin{array}{c}27(22.9 \%) \\
11(9.3 \%)\end{array}$ & $\begin{array}{c}24(14.3 \%) \\
10(6.0 \%)\end{array}$ & 0.072 \\
\hline LVEDD, mm & $57.7 \pm 10,9$ & $55.1 \pm 6.3$ & 0.009 \\
\hline LVEDV, ml & $174.8 \pm 66.2$ & $146.9 \pm 39.7$ & $<0.001$ \\
\hline LVEF, \% & $51.9 \pm 11.2$ & $56.8 \pm 8.5$ & $<0.001$ \\
\hline LVEF $<45 \%$ & $40(30.8 \%)$ & $23(12.8 \%)$ & $<0.001$ \\
\hline NYHA class III-IV & $123(95.3 \%)$ & $154(85.5 \%)$ & 0.020 \\
\hline Angina class III CCS & $27(20.8 \%)$ & $109(60.6 \%)$ & $<0.001$ \\
\hline Angina class IV CCS & $102(78.5 \%)$ & $69(38.3 \%)$ & $<0.001$ \\
\hline EuroScore add, points & $6.5 \pm 1.5$ & $2.4 \pm 1,3$ & $<0.001$ \\
\hline EuroScore $\log , \%$ & $7.29 \pm 4.39$ & $1.93 \pm 0.73$ & $<0.001$ \\
\hline
\end{tabular}

COPD - chronic obstructive pulmonary disease; DM - diabetes mellitus; MI - myocardial infarction; ACS - acute coronary syndrome; CCS - Canadian Cardiovascular Society

On coronarography, the vast majority of patients had a three-vessel disease $(83.3 \%$ and $85.5 \%$ respectively).
Left main stem (LMS) or equivalent coronary artery disease was found in $47.1 \%$ of cases in Group 1 and $45.1 \%$ of cases in Group $2(\mathrm{P}>0.05)$. According to the echocardiography findings, the changes in LV volumes and LVEF were more pronounced in Group 1: LVEF $<45 \%$ was found in $30.8 \%$ of cases in Group I versus $12.8 \%$ of cases in Group $2(P<0.001)$.

The majority of patients in both groups were in NYHA functional classes III and IV (95.3\% in Group 1 and $85.5 \%$ in Group 2). Group 1 included more patients with angina class CCA IV (78.5\% compared to $38.3 \%$ in Group 2, $P<0.001$ ). The risk of mortality, calculated with a EuroSCORE risk calculator, was greater in patients of Group 1 - 6.5 (7.29\%), while in Group 2 it was $2.4(1.93 \%), P<0.001$.

\section{Surgical Technique}

We described the surgical technique in detail earlier. ${ }^{(1)}$ All operations were performed through the median sternotomy. In all patients, the left internal thoracic (or mammary) artery (LIMA) was harvested. In parallel, the great saphenous vein (GSV) was harvested. In a part of patients (70 patients), GSV was harvested endoscopically (Carl Storz, Germany). The pericardium was opened in a standard inverted " $\mathrm{T}$ " fashion. Heparin was administered at a dose of 1 to $1.5 \mathrm{mg} / \mathrm{kg}$ of patient weight (until ACT value $>300 \mathrm{sec}$ ).

The positioning of the heart was carried out with the help of deep pericardial stay suture technique, as well as the use of the vacuum heart positioner (Starfish, Medtronic, Minneapolis, $\mathrm{MN})$. To stabilize the myocardium of the heart in the field of anastomosis, we used commercially available tissue stabilizers (Octopus 4 Tissue Stabilizer, Medtronic, Minneapolis, MN). Temporal occlusion of the coronary artery was performed by applying a silicone vessel loop to the proximal part of artery. After performing an arteriotomy, always, if possible, intracoronary shunts were used (ClearView Intracoronary Shunt; Medtronic).

The sequence of revascularization of coronary arteries differed depending on the presence or absence of occluded arteries, the degree of stenosis, the need to use complex surgical techniques, preferences of the operating surgeon and reaction of hemodynamics to the positioning of the heart and other manipulations.

Revascularization was initiated from an occluded recipient artery. Usually it was either LAD or RCA (or PDA). In cases where it was LAD, first LIMA-LAD anastomosis was constructed and then continued in the usual manner. If it was an RCA (or PDA), then at first, a distal anastomosis with the vein was constructed. Then all proximal anastomoses were constructed on the ascending aorta using a side-bite clamp, and blood supply was restored to the RCA region. This was followed by revascularization of the LAD region. Arteries of the lateral side of the heart were revascularized only after the arteries of the anterior surface (LAD and RCA regions) had been revascularized and received a blood supply. If there were no occluded arteries, revascularization was always initiated with the LAD artery.

If the use of the "aorta-no-touch" technique was planned, first we constructed a T- or Y-graft by anastomosing of the radial artery (or venous conduite) to LIMA. With this technique, the 
sequence of anastomoses looked as follows: diagonal branch (Dx) (LIMA side-to-side anastomosis)-LAD (LIMA end-toside); followed by the circumflex artery and RCA branches (all side-to-side anastomosis and the last one end-to-side). With this technique, after each completed distal anastomosis, the blood flow to the recipient artery was launched.

After the completion of the construction of all grafts, flowmetry (Transit-time flow measurement) was performed to assess the quality of anastomoses (MiraQ, Medistim, Norway). If there was no excess bleeding we neutralized only half the dose of heparin.

Statistical analysis was performed using the statistical software «Statistica». (v6.0, StatSoft, USA). Baseline characteristics were summarized as frequencies and percentages for categorical variables and as mean \pm SEM for continuous variables. For data with normal distribution, intergroup comparisons were performed using Student's t-test. Group comparisons with respect to categorical variables are performed using chi-square tests with Yates correction or, alternatively, Fisher's exact test when expected cell counts were less than 5. A probability value of $P<0.05$ was considered statistically significant.

\section{Results}

Between the two groups, the mean duration of the operation did not differ significantly (232.2 minutes in Group I and 228.0 minutes in Group 2) (Table 2).

Table 2.

Intraoperative data

\begin{tabular}{|c|c|c|c|}
\hline Variable & Group 1 & Group 2 & $P$-value \\
\hline Duration of operation, min & $232.2 \pm 61,1$ & $228.0 \pm 50.3$ & 0.505 \\
\hline $\begin{array}{l}\text { Internal thoracic artery usage } \\
\text { (left or right) }\end{array}$ & $130(100 \%)$ & $180(100 \%)$ & 0.977 \\
\hline $\begin{array}{l}\text { Mean number of grafts per } \\
\text { patient }\end{array}$ & $3.12 \pm 0.7$ & $3.13 \pm 0.8$ & 0.956 \\
\hline$\geq 4$ grafts & $30(23.0 \%)$ & $53(29.5 \%)$ & 0.346 \\
\hline Sequential technique & $15(11.5 \%)$ & $29(16.2 \%)$ & 0.259 \\
\hline Composite grafts & $11(8.5 \%)$ & $11(6.1 \%)$ & 0.389 \\
\hline «LAD first» technique & $98(76.6 \%)$ & $129(72.1 \%)$ & 0.376 \\
\hline Combined grafting technique & $39(30.0 \%)$ & $67(37.2 \%)$ & 0.420 \\
\hline Mean blood loss, $\mathrm{ml}$ & $\begin{array}{c}527.6 \pm 261.2 \\
(200-1500)\end{array}$ & $\begin{array}{c}483.6 \pm 185.7 \\
(100-1200)\end{array}$ & 0.087 \\
\hline $\begin{array}{l}\text { Intraoperative complications: } \\
\text { No complications } \\
\text { PVC } \\
\text { Group PVC } \\
\text { AF, VT, VF, AV-block } \\
\text { Need for inotropic support } \\
\text { Bleeding } \\
\text { Technical difficulties, } \\
\text { intramyocardial coronary } \\
\text { arteries, calcified vessels (or } \\
\text { aorta), etc }\end{array}$ & $\begin{array}{c}107(82,3 \%) \\
1(0.8 \%) \\
1(0.8 \%) \\
5(3.8 \%) \\
7(5.4 \%) \\
2(1.5 \%) \\
7(5.4 \%)\end{array}$ & $\begin{array}{c}156(86.7 \%) \\
0(0.0 \%) \\
0(0.0 \%) \\
6(3.3 \%) \\
3(1.7 \%) \\
4(2.2 \%) \\
11(6.1 \%)\end{array}$ & 0.372 \\
\hline Intraoperative defibrillations & $4(3.1 \%)$ & $4(2.2 \%)$ & 0.348 \\
\hline On-pump conversion & $5(3.8 \%)$ & $0(0.0 \%)$ & 0.008 \\
\hline
\end{tabular}

$P V C$ - premature ventricular contraction; VT - ventricular tachycardia; $V F$ - ventricular fibrillation; $A V$ - atrioventricular
In both groups, LIMA (or RIMA) was used in all patients. The average number of grafts in both groups was more than 3 per patient (3.12 and 3.13 grafts per patient in Group 1 and Group 2, respectively). In 23\% of patients of Group 1 and $29.5 \%$ of patients of Group 2, 4 and more grafts were constructed.

In about $20-23 \%$ of patients in both groups, we used a complex surgical technique in the form of sequential and composite grafts. In Group 2, the sequential grafting technique was used more frequently (16.2\% versus $11.5 \%$ in Group 1) $(P=0.259)$, while in Group 1 we constructed more composite grafts $(8.5 \%$ versus $6.1 \%$ in Group 1$)(P=0.389)$.

As we indicated earlier, the sequence of grafting varied depending on the presence or absence of occluded arteries. In accordance with this, initiation of revascularization with the LAD artery accounted for $76.6 \%$ in Group 1 and $72.1 \%$ in Group $2(P=0.376)$. In the remaining cases, grafting began from other territories (as a rule, it was the RCA region). Mean blood loss in both groups did not differ and amounted to 527.6 $\mathrm{ml}$ and $483.6 \mathrm{ml}$, respectively.

The frequency of intraoperative complications was $17.7 \%$ in Group I and $13.3 \%$ in Group $2(P=0.372)$. As a rule, life-threatening arrhythmias were the prevailing complications (3.8\% in Group 1 and 3.3\% Group 2). About $5.4 \%$ of patients in Group 1 and $1.7 \%$ of patients in Group 2 needed inotropic support until full restoration of normal hemodynamics.

In $5.4 \%$ of cases in Group I and $6.1 \%$ of cases in Group 2 , the surgical team had technical difficulties in conducting the procedure (such as calcified target coronary vessels, intramyocardial coronary arteries, etc.). In addition, there were cases with very calcified aorta (porcelain aorta), which required finding other places to place proximal anastomoses or changing the technique of operation in favor of the "aortano-touch" technique; in two cases adhesive pericarditis was found, which required the conduction of cardiolysis.

We found that all intraoperative conversions to onpump CABG (5 cases or 3.8\%) occurred in patients of Group $1(P=0.008)$. The causes of the on-pump conversion were lifethreatening uncontrolled arrhythmia, critical hemodynamic disturbances, and severe adhesive pericarditis (in one case), which required on-pump support to perform complete cardiolysis. In the immediate postoperative period (Table 3), $51.5 \%$ of patients in Group 1 and $26.8 \%$ of patients in Group 2 needed inotropic support until full restoration of normal hemodynamics $(P<0.001)$ with duration between 6.6 hours in Group 1 and 2.6 hours in Group $2(P<0.001)$. The average duration of ventilation support was 6.8 hours in Group 1 and 5.0 hours in Group 2.

ICU drainage blood losses were $352.2 \mathrm{ml}$ in Group 1 and $371.8 \mathrm{ml}$ in Group 2. Patients of Groups 1 and 2 received on average $329 \mathrm{ml}$ and $376 \mathrm{ml}$ of erythrocyte mass, respectively $(P=0.758)$, as well as on average $308 \mathrm{ml}$ and $280.5 \mathrm{ml}$ per patient of fresh frozen plasma, respectively $(P=0.432)$.

The incidence of nonfatal complications in postoperative period was $18.5 \%$ in Group I and $7.2 \%$ in Group $2(P=0,074)$. Perioperative MI was noted in two cases (1.2\%) in Group 2. Paroxysms of AF were noted in 3.1\% of patients in Group 1 and in $2.8 \%$ of cases in Group 2. Neurologic complications 
(TIA) were noted in one case $(0.8 \%)$ in Group 1 . Acute graft thrombosis was noted in one case $(0.8 \%)$ in Group 1. Respiratory complications were observed in two patients $(2.3 \%)$ in Group 1 and in one patient $(0.6 \%)$ in Group 2.

Table 3.

\section{Postoperative data}

\begin{tabular}{|c|c|c|c|}
\hline Variable & Group 1 & Group 2 & P-value \\
\hline Need for inotropic support & $67(51.5 \%)$ & $49(26.8 \%)$ & $<0.001$ \\
\hline $\begin{array}{l}\text { Duration of inotropic support, } \\
\text { hours }\end{array}$ & $6.6 \pm 10.9$ & $2.6 \pm 6.4$ & $<0.001$ \\
\hline Ventilation time, hours & $6.8 \pm 4.1$ & $5.0 \pm 2,2$ & $<0.001$ \\
\hline Drainage blood loss, ml & $352.2 \pm 179.0$ & $371.8 \pm 177.0$ & 0.343 \\
\hline $\mathrm{RBC}$ transfusion, $\mathrm{ml}$ & $329 \pm 118.9$ & $376 \pm 136.4$ & 0.758 \\
\hline FFP transfusion, $\mathrm{ml}$ & $300.8 \pm 244.3$ & $280.5 \pm 205.7$ & 0.432 \\
\hline $\begin{array}{l}\text { Complications: } \\
\text { No complication } \\
\text { Bleeding, incl. surgical hemostasis } \\
\text { Perioperative MI } \\
\text { Atrial fibrillation } \\
\text { Neurologic complications } \\
\text { Acute renal failure } \\
\text { Acute graft failure (thrombosis) } \\
\text { Respiratory complications } \\
\text { Superficial wound infection } \\
\text { Mediastinitis }\end{array}$ & \begin{tabular}{|c|}
$106(81.5 \%)$ \\
$3(2.3 \%)$ \\
$0(0 \%)$ \\
$4(3.1 \%)$ \\
$1(0.8 \%)$ \\
$1(0.8 \%)$ \\
$1(0.8 \%)$ \\
$3(2.3 \%)$ \\
$5(3.8 \%)$ \\
$0(0.0 \%)$
\end{tabular} & $\begin{array}{c}167(92.8 \%) \\
2(1.2 \%) \\
2(1.2 \%) \\
5(2.8 \%) \\
0(0 \%) \\
1(0.6 \%) \\
0(0 \%) \\
1(0.6 \%) \\
1(0.6 \%) \\
1(0.6 \%)\end{array}$ & $\begin{array}{l}0.074 \\
0.074 \\
0.074 \\
0.074 \\
0.074 \\
0.074 \\
0.074 \\
0.074 \\
0.074 \\
0.074\end{array}$ \\
\hline Mortality & $2(1.5 \%)$ & $2(1.2 \%)$ & 0.763 \\
\hline ICU stay, hours & $49.2 \pm 23.4$ & $46.6 \pm 18.8$ & 0.287 \\
\hline Length of stay (after surgery) & $8.2 \pm 2.9$ & $6.8 \pm 1.9$ & $<0.001$ \\
\hline
\end{tabular}

$R B C$ - red blood cells; FFP - fresh frozen plasma; $M I$ - myocardial infarction; TIA - transitory ischemic attack; ICU-intensive care unit

In Groups 1 and 2, superficial wound infection was noted in $3.8 \%$ and $0.6 \%$ of cases, respectively $(P=0.074)$. In Group 2, one patient $(0.6 \%)$ underwent re-exploration of the mediastinum for hemostasis.

Hospital mortality amounted to $1.5 \%$ in Group 1 and $1.2 \%$ in Group $2(P=0.763)$. The average ICU stay was 49.2 hours in Group 1 and 46.6 hours in Group 2. Patients of Group 1 were discharged home, on average, in 8.2 days, and patients of Group 2 - in 6.8 days $(P<0.001)$.

\section{Discussion}

Literature data present various criteria of high surgical risk in patients undergoing $\mathrm{CABG}$ surgery. Among them are age $>70$ years, low LVEF, the presence of left main stem disease, EuroSCORE $\geq 5$ points, anemia, etc. However, the most common criterion of high surgical risk is EuroSCORE $\geq 5$ points. ${ }^{(2-7)}$ It is known that in general, ${ }^{(8-11)}$ in the initial period of popularization of OPCABG techniques, patients of low surgical risk comprised "typical patient profile."

The expanding of indications on patients of high surgical risk was slowed down by a number of factors, among which, in our opinion, was the lack of information on the results of operations in this group of patients. Numerous studies have compared the results of OPCABG and on-pump CABG, mainly in patients with low surgical risk. In general, these studies could not convincingly demonstrate the advantages of OPCABG in comparison with the conventional on-pump CABG. ${ }^{(2,3,12,13)}$ At the same time, first reports on results of OPCABG surgery in patients of high risk started appearing in the literature. ${ }^{(10)}$ Puskas et al..$^{(5)}$ convincingly demonstrated the advantages of OPCABG over on-pump CABG surgery in a high-risk group of patients. For the first time the advantages of off-pump techniques could be demonstrated in patients grouped by a preoperative risk-stratification index.

In this paper, we present a consecutive series of patients subjected to an isolated OPCABG procedure, which reflects the daily surgical practice of our group. The comparison of the initial preoperative data shows that patients of the high surgical risk group are much older, with a more widespread atherosclerotic process, a higher class of angina and chronic heart failure, among them more persons in the acute phase of MI. In addition, according to ECHO findings, the LV sizes and volumes of Group 1 patients were larger and LVEF was lower. In Group 1, the risk of surgery, calculated with the EuroSCORE calculator, was much higher than in patients of Group 2. Thus, the risk of mortality by EuroSCORE was nearly 4 times higher in Group 1 compared to Group 2 (7.29\% versus 1.93\%). The difference by all these indicators was statistically significant.

In our series of 310 operations with isolated CABG, we managed to perform them off-pump in 305(98.4\%) cases. This rate is one of the criteria of the effectiveness of OPCABG operations. According to different reports, this rate varies between $49 \%$ and $99 \% .^{(2,5,8,11-15)}$ Leading groups in this field, such as J.Puskas, P.Sergeant and others, perform isolated OPCABG in more than $99 \%$ of cases. In addition, one of the indicators is the level of intraoperative conversions to on-pump. This rate varies by different authors from $1 \%$ to $15 \%$. $^{(10,15-17)}$ In our series of operations, this rate amounted to $1.6 \%$, and it is also within the values reached by other leading groups.

In some studies, it was demonstrated that the mean number of grafts per patient was less in OPCABG groups than in on-pump CABG groups. Such data may indicate selection bias or highly selected cases (when OPCABG was performed in patients with one-and two-vessel disease), or incomplete revascularization. Thus, according to some authors, this figure varies from 1.9 to 3.7 grafts per patient. ${ }^{(8,14,18)}$ The mean number of grafts in our series amounted to 3.12 and 3.13 in both groups, respectively, which may indicate an absence of selection and a high level of completeness of revascularization (patients with two- and three-vessel disease in our series). All patients received at least one arterial conduit. In more than $20 \%$ of the cases in both groups, we used complex surgical techniques in the form of constructing sequential and composite grafts.

The level of intraoperative complications was roughly the same in both groups despite the heavier and unstable contingent of patients in Group I. However, we found that all conversions ( 5 for the whole series) occurred only in patients of Group 1. In the literature available to us, we only managed to find several reports devoted to the analysis of conversion causes. ${ }^{(16,17,19)}$ However, a high surgical risk is not highlighted as a conversion risk factor. In the above-mentioned papers, the presence of AF prior to the surgery and history of coronary artery stenting are 
identified as risk factors of conversion. ${ }^{(16)}$ Other risk factors are the presence of left main stem disease, as well as low LVEF. ${ }^{(19)}$ Pullan and co-authors ${ }^{(17)}$ have shown that the planned transition to on-pump operation (conversion) before the occurrence of emergency situations does not increase significantly the rate of complications and mortality in these patients in comparison with patients without conversion. It seems to us that the improvement of results and reduction of the level of complications after onpump conversions lies in the plane of lowering the threshold to the on-pump transition in patients with high surgical risk (i.e. earlier, planned transition with still stable hemodynamics), and the use of heart positioners, intracoronary shunts, and other surgical and anesthetic maneuvers.

As we mentioned above, the peculiarity of the immediate postoperative period in patients of Group 1 was a bigger need for inotropic support, a longer duration time of it, as well as a 1-hour longer duration of respiratory support. For all other basic parameters, we have not identified statistically significant differences between the two groups. The frequency of rhythm disturbances in the groups amounted to $3.9 \%$ and $1.5 \%$, respectively, and did not differ significantly. As is well known, the frequency of atrial fibrillation after conventional on-pump CABG varies between $30 \%$ and $45 \%$. According to different authors, after OPCABG operations, atrial fibrillation happens in $4 \%$ to $26 \%$ of cases. ${ }^{(20)}$ Thus, our results are on the lower edge of the given spectrum. In addition, we did not identify any significant difference in the frequency of nonfatal complications (perioperative MI, neurological disorders, bleeding, etc.) between the groups.

Hospital mortality constituted $1.5 \%$ and $1.2 \%$ respectively. At the same time, the risk of surgical intervention calculated by the EuroSCORE calculator was $7.29 \%$ for patients of Group 1 and $1.93 \%$ for patients of Group 2 . Thus, this result demonstrates a peculiarity of OPCABG surgery: actual mortality does not increase with the increase in surgical risk by EuroSCORE. This is confirmed by other research that studied the performance of EuroSCORE risk calculator on patients undergoing OPCABG surgery. ${ }^{(4,5,7)}$

\section{Conclusion}

The OPCABG operation in patients of high-risk group is a safe method and can be performed without compromising the completeness of myocardial revascularization with the same low mortality as in low-risk patients. The most common type of complication in high-risk patients is on-pump conversion, which at earlier and planned implementation is not reflected significantly at the level of hospital mortality.

\section{$\underline{\text { Study limitations }}$}

The retrospective nature of this study makes it difficult for the authors to draw any definite conclusions. In addition, the number of patients in both groups is relatively small, which may reduce the statistical reliability of the results obtained, or a possible difference is not apparent due to the small number of cases. Nevertheless, the results we obtained clearly demonstrate the safety of performing OPCABG surgery in patients with high surgical risk.

\section{Conflict of interest}

The authors declare that they have no competing interests.

\section{References}

1. Sharipov IM, Yarbekov RR Omonov SKh, Vahidov TZ, Kurbanov RD. Effects of the presence of left main coronary artery disease on the results of off-pump coronary artery bypass grafting surgery. International Journal of Biomedicine. 2017;7(3):175-179.

2. Kim KB, Kim JS, Kang HJ, Koo BK, Kim HS, Oh BH, Park YB. Ten-year experience with off-pump coronary artery bypass grafting: lessons learned from early postoperative angiography. J Thorac Cardiovasc Surg. 2010;139(2):256-62. doi: 10.1016/j.jtcvs.2009.08.040.

3. Møller CH, Perko MJ, Lund JT, Andersen LW, Kelbaek H, Madsen JK, et al. No major differences in 30-day outcomes in high-risk patients randomized to off-pump versus on-pump coronary bypass surgery: the best bypass surgery trial. Circulation. 2010;121(4):498-504. doi: 10.1161/ CIRCULATIONAHA.109.880443.

4. Parolari A, Pesce LL, Trezzi M, Loardi C, Kassem S, Brambillasca $\mathrm{C}$, et al. Performance of EuroSCORE in CABG and off-pump coronary artery bypass grafting: single institution experience and meta-analysis. Eur Heart J. 2009;30(3):297304. doi: 10.1093/eurheartj/ehn581.

5. Puskas JD, Thourani VH, Kilgo P, Cooper W, Vassiliades T, Vega JD, et al. Off-pump coronary artery bypass disproportionately benefits high-risk patients. Ann Thorac Surg. 2009;88(4):1142-7. doi: 10.1016/j. athoracsur.2009.04.135.

6. Shahzad G.Raja, Amrani M. Off-pump coronary artery bypass grafting: outcomes, concerns and controversies. NY: Nova Science Publishers; 2012:146-149.

7. Youn YN, Kwak YL, Yoo KJ. Can the EuroSCORE predict the early and mid-term mortality after off-pump coronary artery bypass grafting? Ann Thorac Surg. 2007;83(6):2111-7.

8. Buffolo E, Branco JN, Gerola LR, Aguiar LF, Teles CA, Palma JH, Catani R. Off-pump myocardial revascularization: critical analysis of 23 years' experience in 3,866 patients. Ann Thorac Surg. 2006;81(1):85-9.

9. Cartier R. Off pump coronary artery bypass surgery. 1st ed. Georgetown: Landes Bioscience; 2005.

10. Chamberlain MH, Ascione R, Reeves BC, Angelini GD. Evaluation of the effectiveness of off-pump coronary artery bypass grafting in high-risk patients: an observational study. Ann Thorac Surg. 2002;73(6):1866-73.

11. Godinho AS, Alves AS, Pereira AJ, Pereira TS. On-pump versus off-pump coronary-artery bypass surgery: a metaanalysis. Arq Bras Cardiol. 2012;98(1):87-94.

12. Sellke FW, Chu LM, Cohn WE. Current state of surgical myocardial revascularization. Circ J. 2010;74(6):1031-7.

13. Stamou SC, Corso PJ. Coronary revascularization without cardiopulmonary bypass in high-risk patients: a route to the future. Ann Thorac Surg. 2001;71(3):1056-61.

14. Emmert MY, Salzberg SP, Seifert B, Schurr UP, Hoerstrup SP, Reuthebuch O, Genoni M. Routine off-pump coronary artery bypass grafting is safe and feasible in high-risk patients with left main disease. Ann Thorac Surg. 2010;89(4):1125-30. doi: 10.1016/j.athoracsur.2009.12.059. 
15. Yaku H, Doi K, Okawa K. Off-Pump coronary artery bypass grafting revisited: experience and evidence from Japan. Ann Thorac Cardiovasc Surg. 2013;19(2):83-94.

16. Maroto Castellanos LC, Carnero M, Cobiella FJ, Alswies A, Ayaon A, Reguillo FJ, García M. Off-Pump to On-Pump Emergency Conversion: Incidence, Risk Factors, and Impact on Short- and Long-Term Results. J Card Surg. 2015;30(10):735-45. doi: 10.1111/jocs.12614.

17. Pullan M, Oo A, Poullis M. Off-Pump Conversion: Inhospital Mortality and Long-Term Survival. Thorac Cardiovasc Surg. 2017;65(4):296-301. doi: 10.1055/s-0035-1566742.
18. Turner WF Jr. "Off-pump" coronary artery bypass grafting: the first one hundred cases of the Rose City experience. Ann Thorac Surg. 1999;68(4):1482-5.

19. Stevens LM, Noiseux N, Avezum A, Ayapati DR, Chen X, Lucchese FA, et al.; CORONARY Investigators. Conversion after off-pump coronary artery bypass grafting: the CORONARY trial experience. Eur J Cardiothorac Surg. 2017;51(3):539-546. doi: 10.1093/ejcts/ezw361.

20. Archbold RA, Curzen NP. Off-pump coronary artery bypass graft surgery: the incidence of postoperative atrial fibrillation. Heart. 2003;89(10):1134-7. 